\title{
Traction-assisted endoscopic submucosal dissection with submucosal tunneling for Barrett's esophagus nodularity
}

Barrett's esophagus (BE) is a premalignant condition with significant risk for esophageal adenocarcinoma. Endoscopic therapy is recommended after mucosal irregularities are found during surveillance [1]. Endoscopic mucosal resection (EMR) is sufficient to determine the depth of invasion. However, endoscopic submucosal dissection (ESD) facilitates en bloc resection and provides better assessment of the lateral margin of the lesion. ESD is technically more difficult than EMR but can be performed when bulky lesions are encountered or when submucosal invasion is suspected $[1,2]$.

A 59-year-old man with BE was found with associated nodularity that measured $2.3 \times 2.4 \mathrm{~mm}$ at $38 \mathrm{~cm}$ from the dental arch ( $\triangleright$ Fig. 1, $\triangleright$ Video 1 ).

The borders of the lesion were marked in a circumferential pattern using the tip of the HybridKnife T-type (Erbe, Tübingen, Germany). The submucosal space was accessed with a horizontal incision about 3-4 cm proximal to the lesion. A submucosal tunnel was created and then extended to the submucosal space below the lesion. The distal part of the lesion was dissected using repeated submucosal injection with saline mixed with methylene blue, followed by short bursts of dissection. The lateral borders of the lesion were dissected from the muscularis propria using mostly the ITknife2 (Olympus, Center Valley, USA). Fibrosis was encountered during dissection and internal traction was applied to facilitate the resection of the lesion. An elastic traction device (Micro-Tech, Nanjing, China) was attached to one of the borders of the lesion ( $\triangleright$ Fig. 2). A second clip (SureClip; Micro-Tech) was then used to pull the plastic ring distal to the lesion to provide sufficient traction, and the submucosal dissection was continued until the lesion was completely resected en bloc. The re-

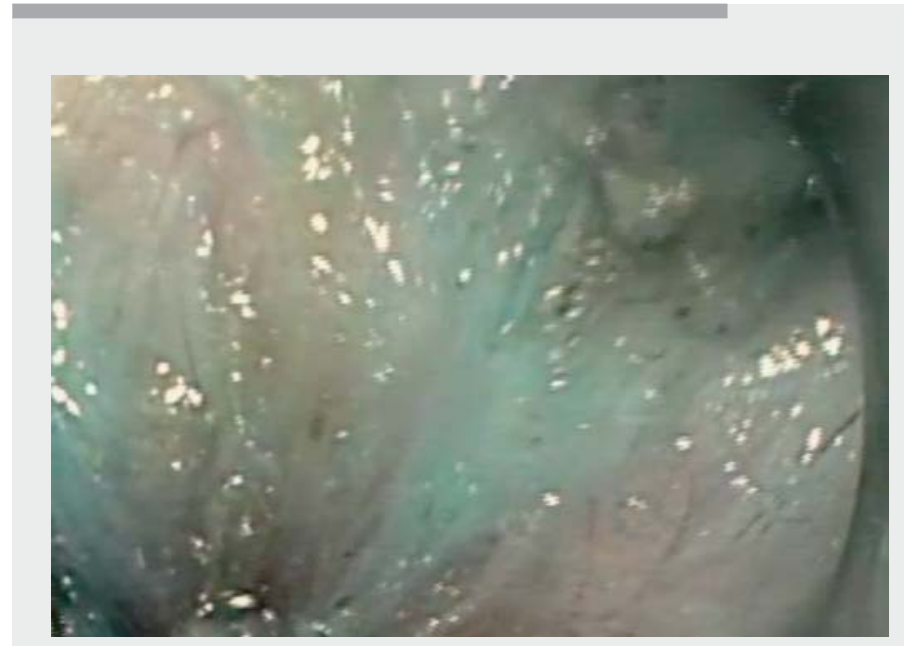

- Fig. 1 Barrett's esophagus nodularity at $38 \mathrm{~cm}$ from the dental arch.

section margins were negative, and the final pathology showed no dysplasia.

This case illustrates perfectly how internal traction facilitates ESD when fibrosis makes dissection difficult.

Endoscopy_UCTN_Code_TTT_1AO_2AC

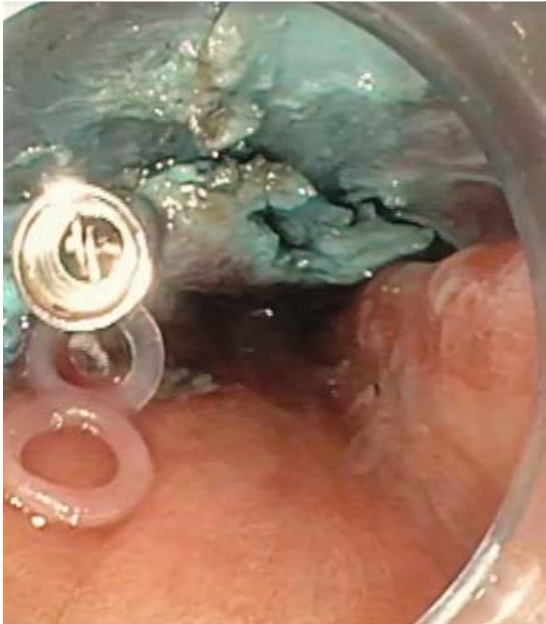

- Fig. 2 Elastic traction device was attached to the lesion to be pulled distally using another clip.

\section{Competing interests}

M. Kahaleh has received grant support from Boston Scientific, MaunaKea, Apollo Endosurgery, Cook Endoscopy, ASPIRE Bariatrics, NinePoint Medical, Merit Medical, Olympus, and Interscope Med.; he is a consultant for Boston Scientific and ABBvie, Concordia Laboratories Inc, ABBvie, and MaunaKea Tech. 
All other authors declare that they have no conflict of interest.

The authors

Rodrigo Duarte-Chavez $\odot$, Marina Kim, Daniel Marino, Michel Kahaleh $\odot$

Department of Gastroenterology, Rutgers Robert Wood Johnson Medical School, New Brunswick, New Jersey, United States

Corresponding author

Michel Kahaleh, MD

Rutgers Robert Wood Johnson Medical School, Department of Gastroenterology, 1 RWJ Place, MEB 491C, New Brunswick, NJ 08901, United States mkahaleh@gmail.com

\section{References}

[1] Weusten B, Bisschops R, Coron E et al. Endoscopic management of Barrett's esophagus: European Society of Gastrointestinal Endoscopy (ESGE) Position Statement. Endoscopy 2017; 49: 191-198

[2] Shaheen N], Falk GW, Lyer PG et al. ACG Clinical Guideline: Diagnosis and management of Barrett's esophagus. Am J Gastroenterol 2016; 111: 30-50

Bibliography

Endoscopy 2022; 54: E275-E276

DOI 10.1055/a-1499-6267

ISSN 0013-726X

published online 18.6.2021

(c) 2021. Thieme. All rights reserved.

Georg Thieme Verlag KG, Rüdigerstraße 14

70469 Stuttgart, Germany
ENDOSCOPY E-VIDEOS

https://eref.thieme.de/e-videos

Endoscopy E-Videos is an open access online section, 回: reporting on interesting cases and new techniques in gastroenterological endoscopy. All papers include a high quality video and all contributions are freely accessible online. Processing charges apply (currently EUR 375), discounts and wavers acc. to HINARI are available.

This section has its own submission website at

https://mc.manuscriptcentral.com/e-videos 